\title{
Actual versus apparent within cell wall variability of nanoindentation results from wood cell walls related to cellulose microfibril angle
}

\author{
Johannes Konnerth · Notburga Gierlinger • \\ Jozef Keckes $\cdot$ Wolfgang Gindl
}

Received: 23 April 2009/ Accepted: 4 June 2009/Published online: 23 June 2009

(C) The Author(s) 2009. This article is published with open access at Springerlink.com

\begin{abstract}
Hardness and elastic modulus of spruce wood cell walls parallel to their axial direction were investigated by means of nanoindentation. In the secondary cell wall layer S2 of individual earlywood and compression wood tracheids, a systematic pattern variability was found. Several factors potentially affecting nanoindentation results were investigated, i.e. specimen orientation related to the indenter tip, cutting direction during specimen preparation, tip geometry, specimen and fibre inclination, respectively, and finally micro fibril orientation. Mechanical property measurements were correlated with structural features measured by confocal Raman spectroscopy. It was demonstrated that very high variability in the measurement of micromechanical cell wall properties can be caused by unintentional small fibre misalignment by few degrees with regard to the indentation direction caused by sub-optimal specimen preparation.
\end{abstract}

J. Konnerth $(\bowtie) \cdot$ W. Gindl

Department of Material Sciences and Process Engineering, Institute of Wood Science and Technology, BOKU-University of Natural Resources and Applied Life Sciences,

Peter Jordanstrasse 82, 1190 Vienna, Austria

e-mail: johannes.konnerth@ boku.ac.at

N. Gierlinger

Department of Biomaterials, Max-Planck Institute of Colloids and Interfaces, Potsdam, Germany

J. Keckes

Department Materials Physics, Erich Schmid Institute of Materials Science, Austrian Academy of Sciences, University of Leoben, Leoben, Austria

\section{Introduction}

In technical terms, the most important attribute of wood is its excellent mechanical performance at comparably low weight, which enables tree growth up to stem heights beyond $100 \mathrm{~m}$, as well as the use of wood as structural material. In order to develop a thorough understanding of the bulk properties of wood, it is crucial to take into account its distinct hierarchical structure [1] at all levels of organisation. Variability abounds on the macroscopic level, where the presence of knots, the direction of fibres with respect to the stem axis and the presence of radial density variations such as tree rings, are the most important causes of differing mechanical properties. On the microscopic level, differences between individual types of cells and tissues have to be considered and, at lower scale, also the cell wall of an individual cell is far from homogeneous. A wood cell wall is built-up of layers which differ in their chemical composition, e.g. cellulose content, but also in their structure, the most important structural feature being variability in the angle of cellulose fibrils with regard to the longitudinal cell axis. Since the secondary cell wall 2 (S2) is by far the thickest cell wall layer $(>80 \%$ of the total thickness) in wood cell walls, research efforts concentrate on this cell wall region. Different approaches for measuring mechanical properties at the microscopic level can be found in literature. Using single fibre tensile tests, individual wood fibres were first characterised by Page et al. [2], and many studies using this technique followed [3-5]. As a new approach for micromechanical characterisation, nanoindentation was introduced in wood science by Wimmer et al. [6]. A minimum indent size in the order of $100 \mathrm{~nm}$ allows to characterise not only the mechanical properties of the $\mathrm{S} 2$, but also to assess mechanical variability within this cell wall layer. Nanoindentation was used in a variety of studies 
to characterise wood and similar cellulosic materials [614]. As nanoindentation was developed for hard, thin, homogenous and isotropic materials like thin metal films, it can be applied to anisotropic materials like wood only with some caution. For example, using the standard Oliver and Pharr theory [15] with conical indenters, correct absolute values for the longitudinal elastic modulus of wood cell walls [9, 12] or cellulose fibres [16] cannot be determined. However, it was shown that nanoindentation is very well applicable to wood for comparative studies where, e.g. different treatments of wood like melamine treatment [7] or adhesives penetration [11] were analysed. For such studies, any unintended variation should be eliminated, e.g. by comparing cells from one tree ring only [12]. Finally, it was demonstrated recently that the epoxy embedding material combined with the embedding procedure used for most nanoindentation studies on wood studies is not capable of penetrating the cell wall [17] and can therefore be excluded as possible source of error. A recent study showed that nanoindentation on wood is also feasible without the use of embedding material, if the structural compliance of the wood specimen is determined and considered for analysis [10].

Even when possible known sources of unwanted variation are eliminated, nanoindentation results from wood cell walls are affected by high variability [6, 18]. Therefore, this study is dedicated to a detailed position-resolved study of variability of nanoindentation results within individual cells. Possible factors biasing measurements are analysed. By analysing the same cells characterised by nanoindentation with confocal Raman microscopy, insights into chemical as well as structural variability can be gained within the cell wall layers of one single wood fibre [19, 20]. The combination of the two methods thus provides the potential to explain changes in mechanical properties based on structural variability within the cell wall and exclude or confirm methodological errors.

\section{Materials and methods}

Measurement of cellulose microfibril angle by means of wide angle X-ray scattering

Using a conventional microtome, slices with a thickness of $500 \mu \mathrm{m}$ in the radial anatomical direction were cut from the pieces of spruce wood (Picea abies) with dimensions of $10 \mathrm{~mm} \times 10 \mathrm{~mm} \times 10 \mathrm{~mm}$. Different slices containing early wood, late wood and compression wood were selected in order to ensure a high variability in cellulose microfibril angle (MFA). The average angle of cellulose microfibrils with regard to the longitudinal cell axis, which is the most important structural parameter determining cell

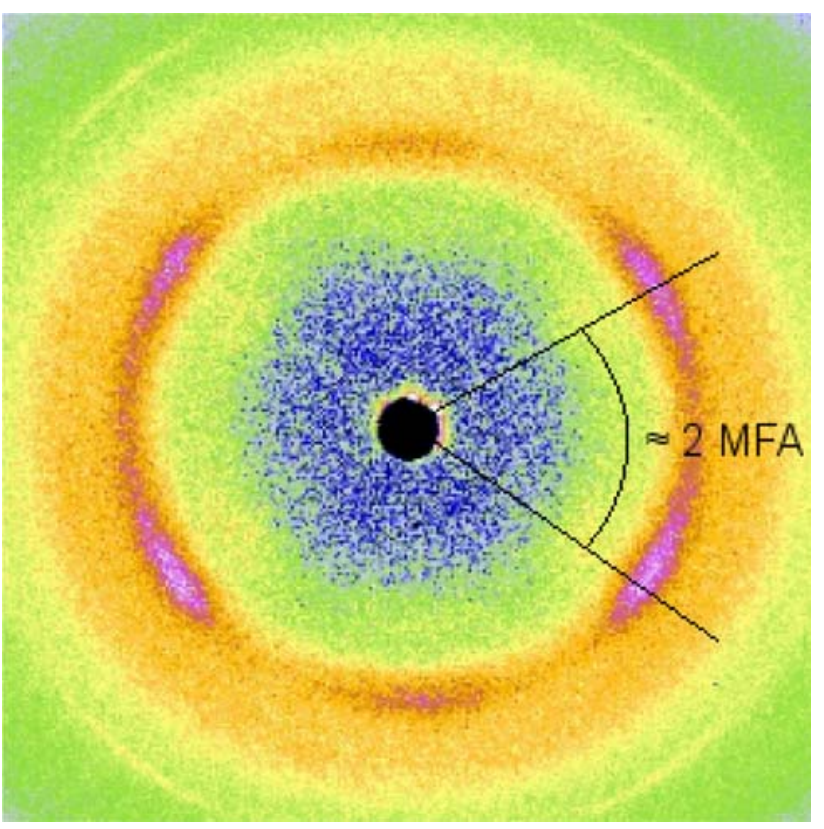

Fig. 1 Two-dimensional detector image from a WAXS experiment with spruce compression wood. The most intense reflections correspond to the cellulose 200 reflection, which is at an angle of $90^{\circ}$ with regard to the c-crystallographic axis of cellulose I. The angle between the two reflections indicated in the image above corresponds to $2 *$ MFA, since it originates from cellulose situated in double-cell walls with spiral texture

wall mechanics, was characterised using wide angle X-ray scattering (WAXS). For this purpose, the thin wood slices were exposed to X-ray radiation in a Bruker Nanostar device, and 2D detector images as shown in Fig. 1 were recorded. The cellulose MFA was evaluating the azimuthally scattering intensity distribution of the cellulose 200 reflection (Fig. 1).

\section{Nanoindentation}

After MFA measurement, pieces with a length of $2 \mathrm{~mm}$ and a width of $2 \mathrm{~mm}$ were cut from the 500- $\mu \mathrm{m}$ thick wood slices and embedded in AGAR epoxy (AGAR low viscosity resin kit, AGAR Scientific Ltd., Stansted, UK) by alternating vacuum-pressure treatment. A smooth surface was cut using a Leica Ultracut-R microtome equipped with a Diatome Histo diamond knife. In order to control possible effects of the cutting direction on surface smoothness and, in consequence, surface mechanical properties as measured by the nanoindenter, samples were cut with the cutting direction strictly parallel to radial or tangential cell walls. The embedded and sectioned specimens were glued to metal discs with epoxy resin in order to be clamped magnetically to the nanoindenter sample stage. In order to analyse a potential influence of sample inclination with respect to the probe tip, samples were also mounted on a 
steel plate with controllable tilt. The sample preparation procedure is described in detail elsewhere [17].

Nanoindentation (NI) experiments were performed with a Hysitron TriboIndenter system (Hysitron Inc., Minneapolis, USA, www.hysitron.com) equipped with either a three-sided pyramid diamond indenter tip (Berkovich type, $142.3^{\circ}$ total included angle) or a cone diamond tip with a total included conical angle of $60^{\circ}$ and $<150 \mathrm{~nm}$ tip radius.

Experiments were performed in load-controlled mode using a pre-force of $1.5 \mu \mathrm{N}$ and a three-segment load ramp: load application within $3 \mathrm{~s}$, hold time $20 \mathrm{~s}$ and unload time $3 \mathrm{~s}$. Depending on the sample to be characterised, the peak load was varied. A peak load of $150 \mu \mathrm{N}$ resulted in indentation depths of up to $150 \mathrm{~nm}$ in the case of the Berkovich tip and up to $370 \mathrm{~nm}$ for the cone tip. A reduced peak load of $30 \mu \mathrm{N}$ (Berkovich tip) and $20 \mu \mathrm{N}$ (cone tip) lead to a reduced indentation depth of $70 \mathrm{~nm}$ for both tip geometries. The distance between indents was usually chosen to be thrice the indentation diameter.

For accurate positioning of the indents, an imaging scan of the cell wall was performed on the indenter stage by means of in situ scanning probe microscopy (SPM) with the indenter tip and a scan size of $10 \mu \mathrm{m} \times 10 \mu \mathrm{m}$ up to $50 \mu \mathrm{m} \times 50 \mu \mathrm{m}$. Indent positions on the cell walls were marked on the SPM image and executed from this mode. After indentation, the position of all indents was verified by SPM. Both indents near cell wall borders with possible influence from surrounding embedding material and indents placed in the epoxy embedding material were removed from the data set and are not shown in the results. The reduced elastic modulus as well as the hardness was calculated from load-indentation depth curves recorded during NI experiments according to the Oliver and Pharr method [15].

\section{Raman spectroscopy}

Spectra were acquired with a confocal Raman microscope (CRM200, Witec, Ulm, Germany) equipped with a piezo scanner (P-500, Physik Instrumente, Karlsruhe, Germany) and an water immersible objective from Nikon $(60 \times, \mathrm{NA}=$ 0.8 ). A linear polarised laser (diode laser, $\lambda=785 \mathrm{~nm}$, CrystaLaser, Reno, NV, USA) was focused with a diffraction limited spot size (0.61 $\lambda / \mathrm{NA})$ and the Raman light was detected by a deep depletion spectroscopic CCD camera (DU401A-BR-DD, Andor, Belfast, North Ireland) behind a grating (300 $\mathrm{g} \mathrm{mm}^{-1}$, NIR-blazed) spectrograph (Acton, Princeton Instruments Inc., Trenton, NJ, USA). The laser power on the sample was approximately $100 \mathrm{~mW}$. For the mapping an integration time of $0.5 \mathrm{~s}$ and $0.33 \mu \mathrm{m}$ steps were chosen and every pixel corresponds to one scan.

The ScanCtrlSpectroscopyPlus software (Witec) was used for measurement setup and image processing. Raman images were achieved by using a sum filter, integrating over defined wavenumber regions in the spectrum. The filter calculates the intensities within the chosen borders and the background is subtracted by taking the baseline from the first to the second border. The chemical images enabled us to separate regions differing in chemical composition and/or cellulose orientation and to mark defined areas in order to calculate average spectra from these regions of interest for a detailed analysis.

\section{Results and discussion}

\section{Microfibril orientation}

The results of WAXS measurements for the characterisation of cellulose MFA show sufficient variability for the purpose of this study. Two samples of each earlywood and latewood were measured. In both types of tissue, one sample showed very low MFA $\left(0 \pm 3^{\circ}\right)$. Additionally, one latewood sample $\left(9 \pm 2^{\circ}\right)$ and one earlywood sample $\left(10 \pm 2^{\circ}\right)$ showed intermediate MFA. In comparison, the MFA of the two mild compression wood samples offered significantly higher MFA with $18 \pm 2^{\circ}$ and $17 \pm 2^{\circ}$.

\section{Results from nanoindentation}

As expected on the basis of previously published studies [8, 18], high variability was found for the elastic modulus and the hardness derived from nanoindentation measurements in earlywood, latewood and compression wood. In contrast to earlier investigations, part of the mechanical variability can be attributed to artefacts found in sample preparation based on the results of this study. In the following section, we first present all nanoindentation results, describe factors possibly influencing and apparently not influencing measurements and then correlate these results with structural data.

A graphical representation of the variability of elastic modulus and hardness from nanoindentation experiments in selected compression wood cells is given in Fig. 2. In a very consistent manner, regions of high modulus (up to 17.97 $\mathrm{GPa}$ ) and low modulus (on average 8.20 GPa) are found within the secondary cell wall two (S2) of individual cells. Interestingly, regions of high modulus in one cell wall are often accompanied by low moduli in the neighbouring cell wall, as illustrated in more detail in Fig. 3.

In contrast to the elastic modulus, the variability found in hardness of cells only partly correlates with the distribution of the modulus, as seen in Fig. 2. This is in good agreement with an earlier study proposing that hardness and elastic modulus, as measured by nanoindentation, are related to different structural parameters in the wood cell wall [8]. In 
(a)
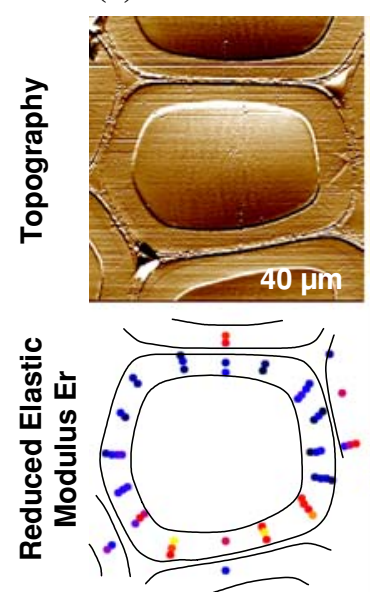

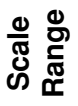

Er 6-24 GPa

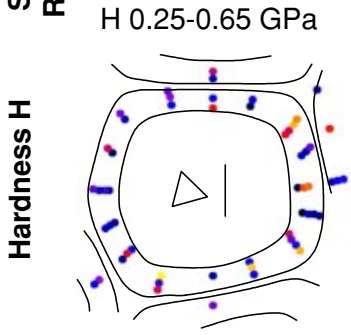

(b)
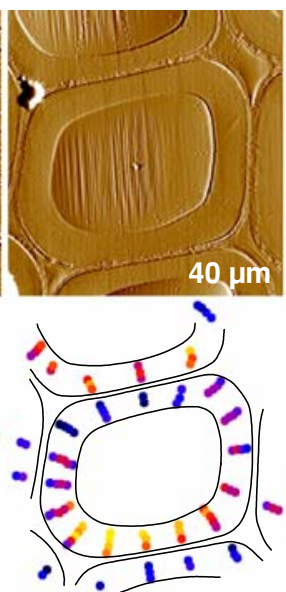

Er 12-28 GPa

$$
\min
$$

$\mathrm{H}$ 0.4-0.85 GPa

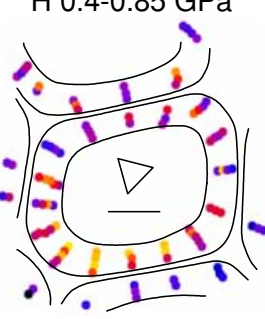

(c)

(d)
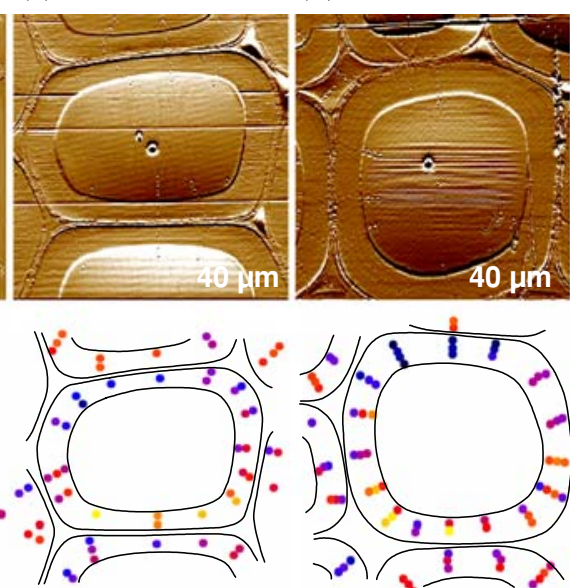

Er 4-18 GPa

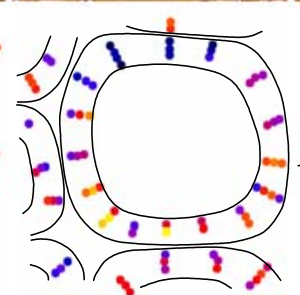

Er 7-17 GPa

(e)
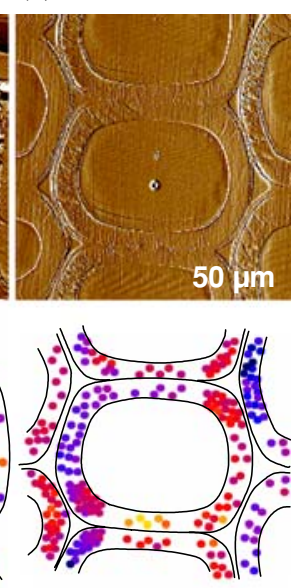

Er 8-22 GPa

Fig. 2 Results of nanoindentation measurements of selected compression wood cells. Topography of wood cells by means of in situ SPM with corresponding picture size. Reduced elastic modulus and hardness by means of nanoindentation measurements with distribution of results within the corresponding cell walls $(\mathbf{a}-\mathbf{e})$. Scale range

individually selected for each diagram from minimum (min) to maximum (max). Triangles and circles with base line displayed in the last row (hardness) indicate indenter tip geometry and orientation used: a, b Berkovich tip, c-e $60^{\circ}$ cone tip

Fig. 3 (Left) SPM image of a wood cell after a nanoindentation experiment. (Right) Significant difference in elastic modulus found in the neighbouring cell walls (e.g. cell walls $\mathrm{A}$ and $\mathrm{B}$ ) of a double cell wall
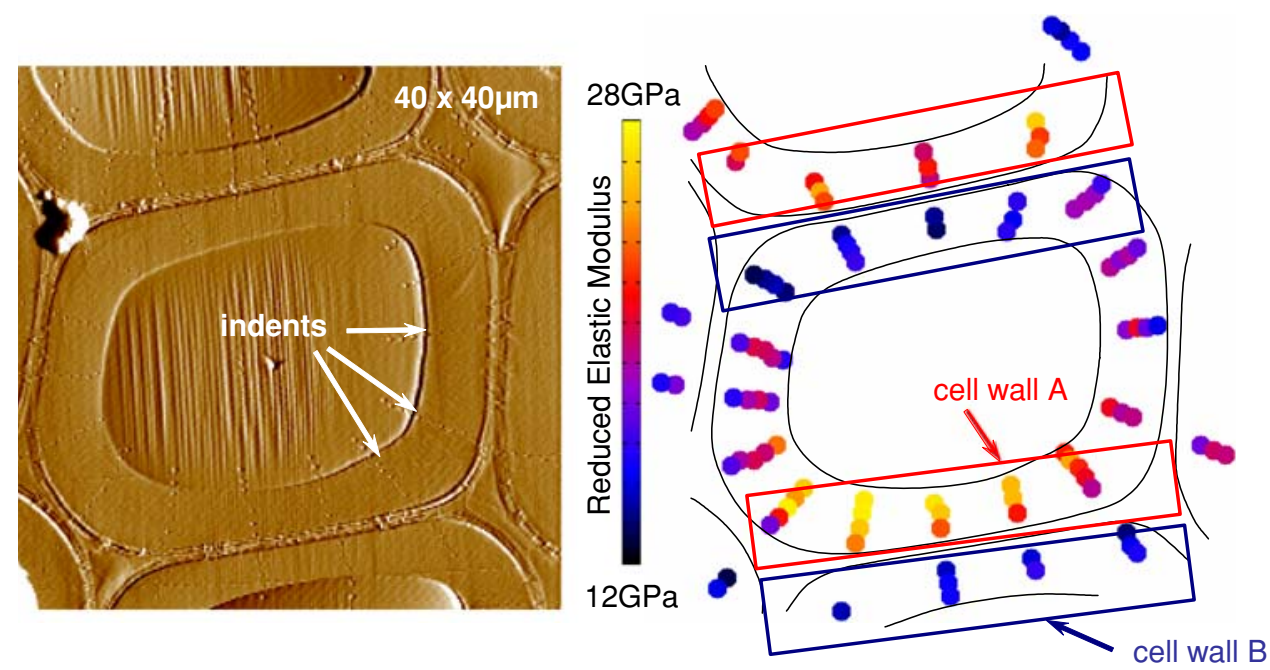

this study it was put forward that the elastic modulus of the wood cell wall is strongly correlated to the cellulose MFA, which is in good agreement with results from tensile tests with single wood fibres [21], whereas hardness was connected to the cell wall matrix. Variability of the pattern shown in Fig. 2 was already observed in earlywood tracheids in a nanoindentation study on adhesive bonding of wood [18]. In this study a model was proposed based on a potential 
contribution of the geometry of the three-sided Berkovich indenter tip. It was put forward that not only the absolute MFA of a cell wall, but also the sign of the angle with respect to the indentation direction was of significance when a Berkovich indenter was used. In order to assess a potential influence of the indenter geometry more deeply than done in this earlier study, the experimental set-up was varied in the following ways.

Firstly, an aspect of the geometry of the Berkovich indenter tip related to the specimen (and therefore related to the cellulose fibrils) was changed in this study, i.e. the specimens were turned by $90^{\circ}$ (Fig. $2 \mathrm{a}, \mathrm{b}$ ). This results in cellulose microfibrils pointing either towards an edge of the Berkovich pyramid or towards a flank of the pyramid. Contrary to the assumptions expressed earlier no changes in systematic variability of the pattern could be observed.

Secondly, the three-sided pyramid Berkovich indenter was replaced by a $60^{\circ}$ cone tip which should not be prone to the proposed geometric influence in terms of orientation related to the specimen, due to its circular design. As seen in Fig. 2c-e, the observed pattern of variability of the modulus of elasticity persisted also with this new indenter tip shape. In contrast, the absolute value for the elastic modulus of cell walls decreased significantly for the cone tip compared to the Berkovich indenter (Fig. 4). The mean value for all measurements performed with the cone tip was $E_{\mathrm{r}} 10.49 \mathrm{GPa}$, whereas the mean value for Berkovich measurements was $E_{\mathrm{r}} 15.1 \mathrm{GPa}$. Differences of hardness measurements performed with both Berkovich and cone tip are not obvious according to Fig. 4 ( $H$ cone $0.427 \mathrm{GPa}, H$ Berkovich $0.477 \mathrm{GPa}$ ). When nanoindentation measurements are performed in homogeneous and isotropic materials such as embedding epoxy used in this study, or in fused silica used for calibration purposes, the same absolute values are obtained irrespective of the indenter geometry used. This is not the case in anisotropic materials, where the elastic modulus measured by nanoindentation can be regarded as a mixture of the moduli along all principal material axes due to the three-dimensional stress state found under the indenter body [9, 16, 22, 23]. This phenomenon is more pronounced with increasing degree of anisotropy of the material in question. In wood fibres, e.g. the modulus in longitudinal (or fibril) direction is supposed to be up to ten times higher [9] than perpendicular to it. When a flat tip like Berkovich (142.3 $3^{\circ}$ included angle) is used and the indent is performed parallel to the direction of the fibre, the resulting modulus should therefore be closer to the (true) tensile modulus of the fibre than when a much sharper $60^{\circ}$ cone tip is used, which is seen in Fig. 4.

Thirdly, also the direction of cutting during sample preparation was considered as a potentially biasing factor affecting our measurements. It is known from macroscopic cutting studies with wood that the surface roughness

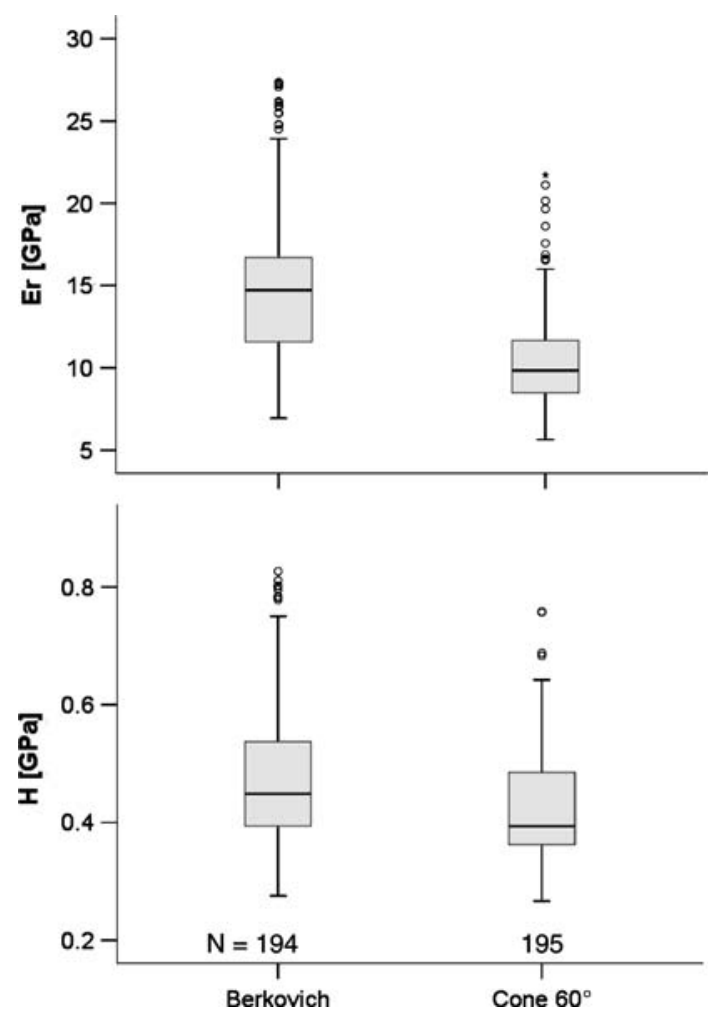

Fig. 4 Comparison of reduced elastic modulus $E_{\mathrm{r}}$ and hardness $H$ obtained from nanoindentation measurements using either Berkovich or cone tip on compression wood cells (box plots indicate median, 25 and $75 \%$, maximum and minimum value which are not outliers, outlier $O$, extreme value *)

depends on the direction of cutting with respect to the direction of grain. Cutting "with" the grain, i.e. the angle between the cutting direction and the wood fibres is less than $90^{\circ}$ leads to smooth surfaces, whereas cutting "against" the grain (angle $>90^{\circ}$ ) leads to high surface roughness. A similar effect is also seen when wood tracheids are cut "with" or "against" the microfibril direction. Therefore, the tracheids shown in Fig. 2a-d were cut in tangential anatomical direction, whereas the cells in Fig. 2e were cut in radial anatomical direction. Again an assessment of the distribution of the elastic modulus shows high moduli for outer tangential cell walls and low moduli for inner tangential cell wall, irrespective of the cutting direction chosen. To summarise the results presented in Fig. 2 it can be said that the pattern of spatial variation in the elastic modulus is independent of tip geometry, position of the tip with regard to cellulose microfibrils (Berkovich) and cutting direction.

Motivated by the results presented so far, further indentation experiments were performed in cell walls of specimens with different average MFA. The results of these measurements confirmed very high variability for nanoindentation measurements in general (Fig. 5). Similar to the 
Fig. 5 Dependence of reduced elastic modulus $E_{\mathrm{r}}$ and hardness $H$ on cell wall MFA
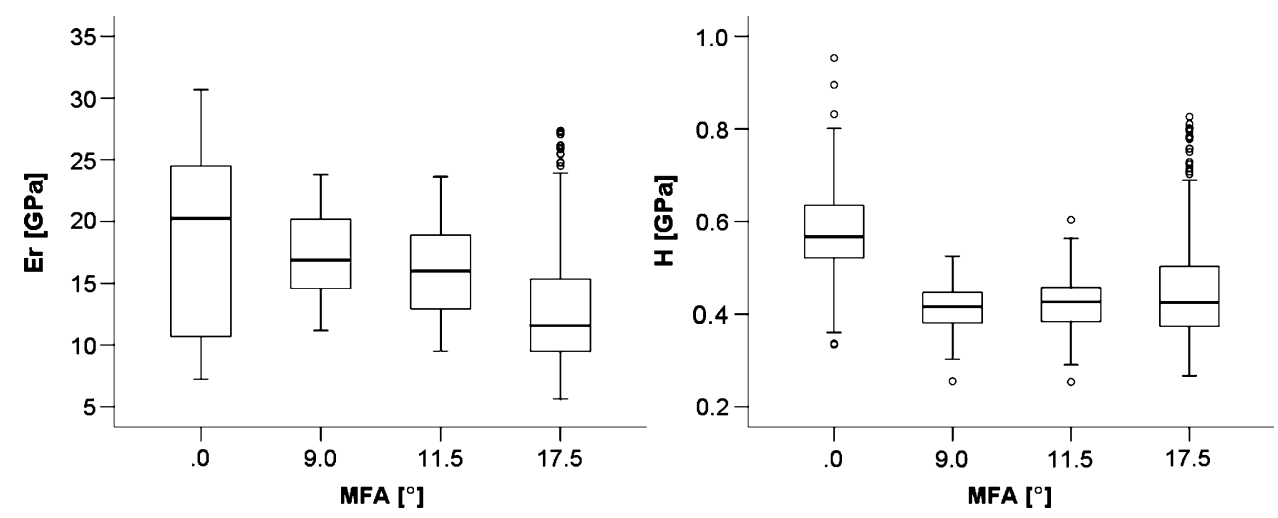

detailed results shown in Fig. 2 for compression wood cell walls, the pattern of variability of the elastic modulus showed clear differences in absolute values between neighbouring cell walls in double cell walls. The magnitude of these differences was between 2 and $6 \mathrm{GPa}$.

At this point, the question of possible structural causes for the observed consistent pattern of variability arose. Therefore, the orientation distribution of cellulose microfibrils within one cell wall of a specimen used for nanoindentation was studied in detail by means of confocal Raman microscopy. Changes in lignin distribution and cellulose orientation can be followed within individual wood cells by integrating over selected wavenumber regions comprising the relevant Raman bands [19, 20]. Figure 6a shows the lignin distribution in a cell wall (mild compression wood) by integrating from 1539 to $1709 \mathrm{~cm}^{-1}$. Typically for all wood tissues high lignin content (bright yellow) is found in the cell corners connecting the wood fibres. Characteristics for compression wood are that these cell corners can also be lignin free (right side) and instead of high lignin content in the compound middle lamella high lignification is found in a relatively thick S1 layer. No differences in lignin content are detected within the S2 layer (Fig. 6a). When a linear polarised laser is applied, changes in band intensities of cellulose attributed bands can arise from changes in cellulose content as well as from changes in cellulose orientation [20]. Nevertheless integrating from 351 to $400 \mathrm{~cm}^{-1}$, comprising a band attributed to heavy atom stretching and not severely influenced by orientation [24], reflects more changes in cellulose content (Fig. 6b). A contrary picture to the lignin distribution is derived showing high cellulose content in the S2 layer, whereas cell corners and the S1 layer show less intensity. By restricting the integration area to the band at $1096 \mathrm{~cm}^{-1}$, attributed to $\mathrm{C}-\mathrm{O}-\mathrm{C}$ stretching and very sensitive to orientation [24], areas with higher MFA can be worked out in the direction of laser polarisation $[19,20]$. By this the $S 1$ layer shows the highest intensity because of high MFA, but also significant differences between two neighbouring cell walls in one double cell wall become visible. For example, higher MFA is measured in cell wall A compared to adjacent cell wall B in Fig. 6c. To evaluate and finally proof the differences found by the imaging approach, average spectra were derived selectively from the adjacent cell walls within one double cell wall (Fig. 7). As indicated already in the imaging approach the most pronounced changes are found in the $\mathrm{CC}$ and $\mathrm{CO}$ stretching region with the major band at $1096 \mathrm{~cm}^{-1}$. This band becomes very intense when the direction of the incident laser polarisation is parallel to the chain direction of the cellulose molecule. Measuring single isolated spruce fibres with a very low MFA $\left(<10^{\circ}\right)$ with the laser polarised parallel along the fibre and turning the laser polarisation in $3^{\circ}$ degree steps until polarisation is perpendicular to the fibre direction, allows to evaluate the characteristic band height changes in respect to cellulose and laser polarisation. The inset of Fig. 7 shows representative spectra for the cellulose chain and laser direction perpendicular to each other (grey line) and changed about $30^{\circ}$ (black line). The band height ratio (1122/1096, Fig. 7, red line) of the cell wall B (Fig. 6c) fits well with laser and cellulose direction perpendicular to each other (Fig. 7 inset, grey line) and as the S2 layer spectra are derived from a cross section, this means that the cellulose in this layer is arranged almost parallel $\left(0-10^{\circ}\right)$ along the fibre. The band height ratio (Fig. 7 blue line) of cell wall A (Fig. 6c) corresponded well to a change in cellulose/polarisation direction of $30^{\circ}$ (Fig. 7 inset, black line). From this we conclude that there is indeed a difference of about $30^{\circ}$ in cellulose orientation between the cell walls A and B in Fig. 6c.

The results of confocal Raman spectroscopy, with high differences in MFA between adjacent cell walls, can be interpreted as strong evidence for a misalignment between the longitudinal wood fibre axis and the direction of indentation according to the scheme shown in Fig. 8. Therefore, in a next step, an experiment was performed with carefully aligned specimens embedded at a controlled 

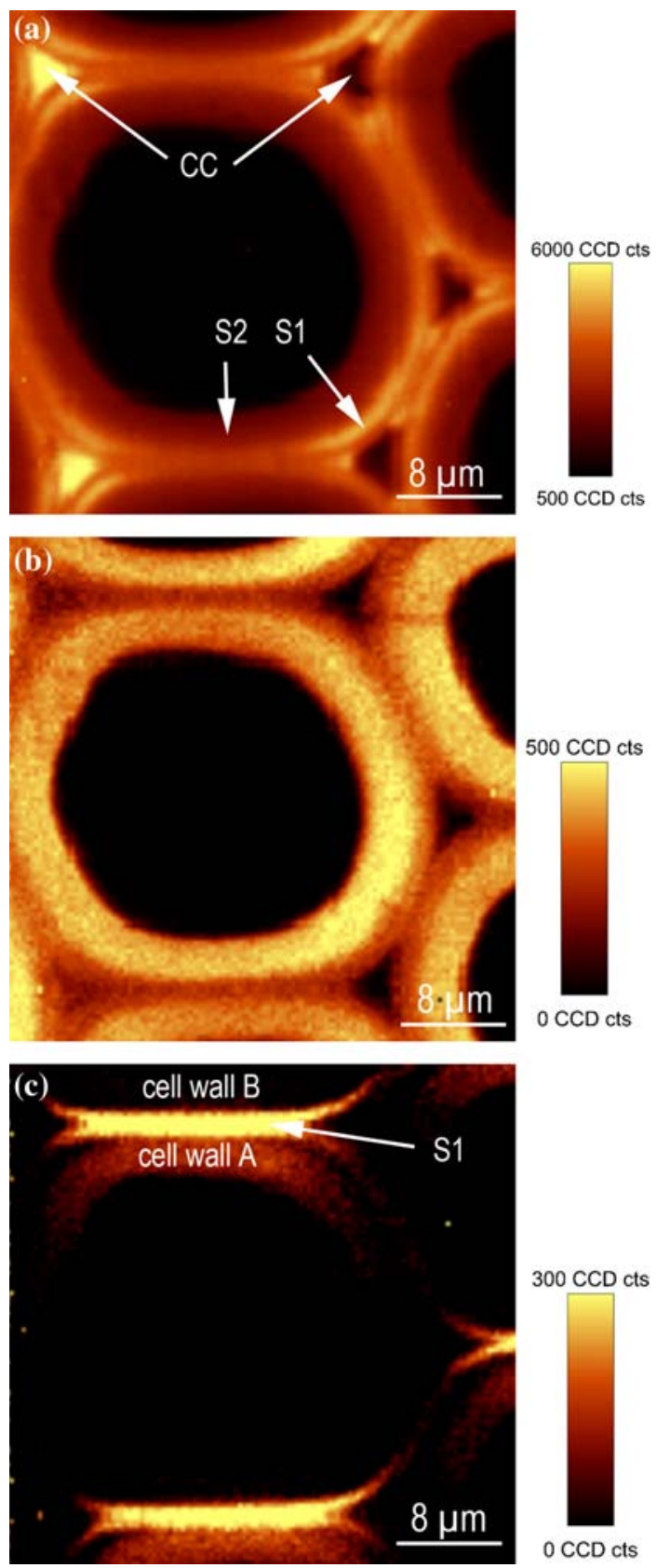

$300 \mathrm{CCD}$ cts

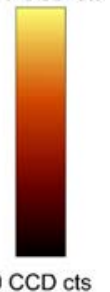

Fig. 6 a-c Raman images $(40 \mu \mathrm{m} \times 40 \mu \mathrm{m})$ of mild compression wood calculated by integrating from 1539 to $1709 \mathrm{~cm}^{-1}$ (a, lignin), from 351 to $400 \mathrm{~cm}^{-1}$ (b, cellulose) and from 1056 to $1102 \mathrm{~cm}^{-1}$ (c, cellulose orientation), accentuating regions with high MFA in $x$-direction, which corresponds to the direction of laser polarisation

misalignment of $+6^{\circ}, 0^{\circ}$ as reference, and $-6^{\circ}$ with regard to the direction of indentation. Results of this experiment shown in Fig. 9 confirm the assumption based on Raman results. No difference in the elastic modulus was found between neighbouring cell walls of a double cell wall at $0^{\circ}$ alignment, whereas clear, opposing differences of the same magnitude of about $20 \%$ were found at inclinations of $+6^{\circ}$ and $-6^{\circ}$, respectively.

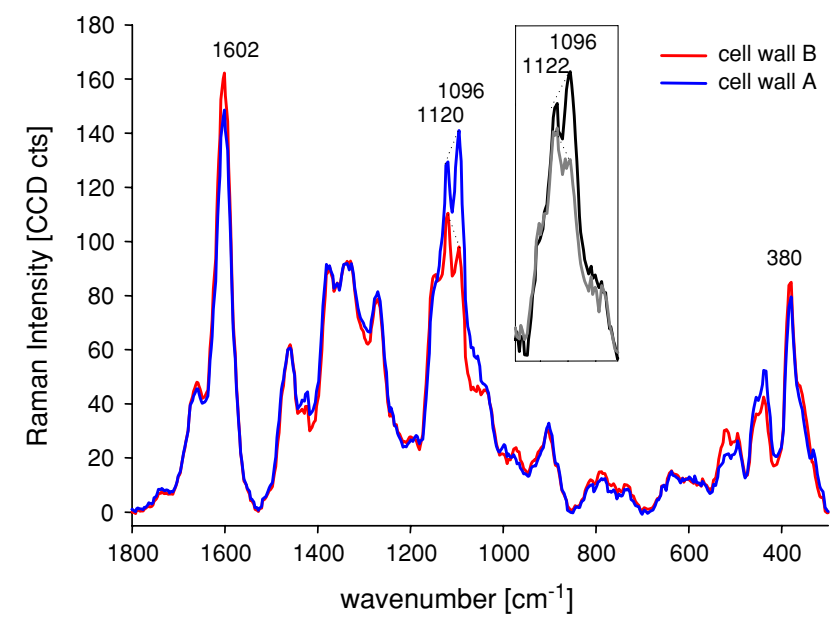

Fig. 7 Fingerprint region of baseline corrected average Raman spectra extracted from tangential cell wall B (red line) and cell wall A (blue line) S2 layer of mild compression wood. The inset shows the peak height ratio of the 1122 and $1096 \mathrm{~cm}^{-1}$ band, when the laser polarisation direction is perpendicular to the cellulose chain (grey line) and changed about $30^{\circ}$ (black line)

\section{Conclusion}

Motivated by the high and partially unexplained variability in nanoindentation results performed with wood cell walls found in earlier investigations, a number of potentially influencing factors were studied. The following conclusions can be drawn.

- The aspect of the geometry of the Berkovich indenter tip resulting in the fact that, in extreme cases, cellulose microfibrils point either towards an edge of the pyramid or towards a flank of the pyramid, does not significantly affect results.

- Replacing the flat Berkovich pyramid by a $60^{\circ}$ cone indenter leads to a significant reduction of resulting values for the elastic modulus but not for hardness.

- The direction of cutting during sample preparation with a diamond knife_- "with" or "against" cellulose microfibril orientation-does not significantly affect results.

- Misalignment between the longitudinal cell axis and the direction of indentation leads to significant differences in apparent microfibril orientation within cell walls as demonstrated by confocal Raman spectroscopy. Such misalignment was identified to be the cause of systematic differences between the elastic moduli of neighbouring cell walls within one double cell wall observed in this and in earlier studies.

- As observed in earlier studies, patterns of variability associated with cellulose microfibril orientation obvious for the elastic modulus are less clear or absent for cell wall hardness. 
Fig. 8 Schematic illustration of the influence of cell inclination $\left(\mathbf{a} 0^{\circ}, \mathbf{b} 1^{\circ}\right)$ on the orientation of microfibrils related to the indentation axis

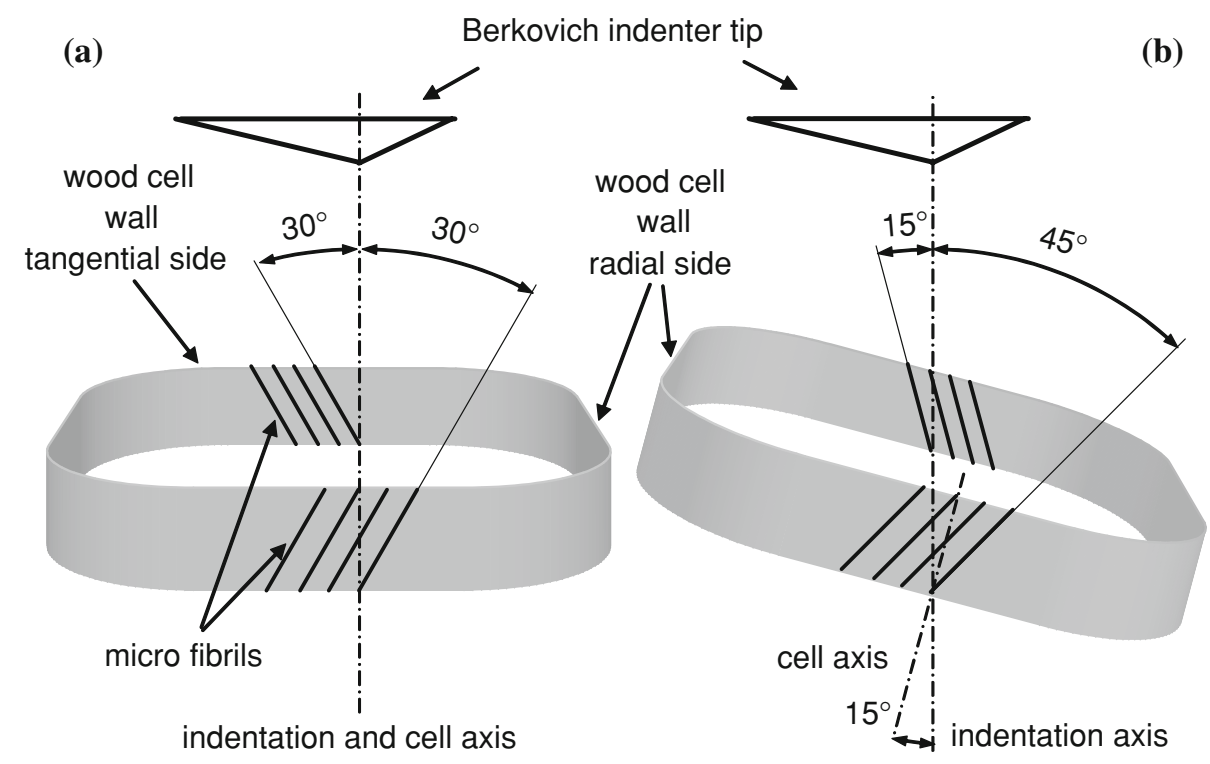

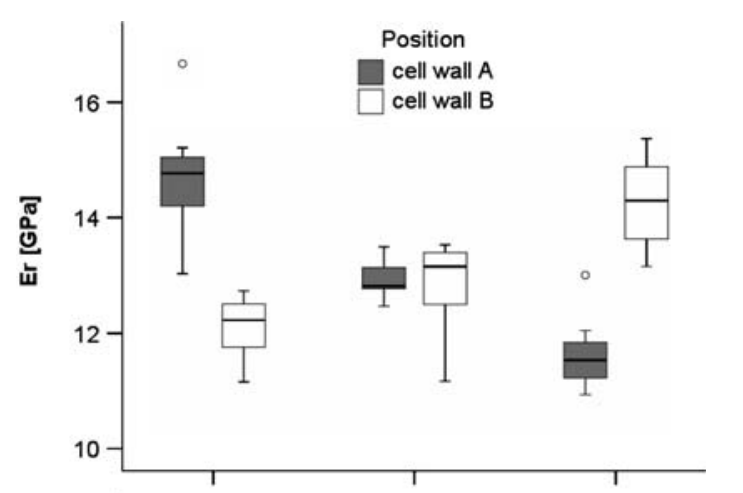

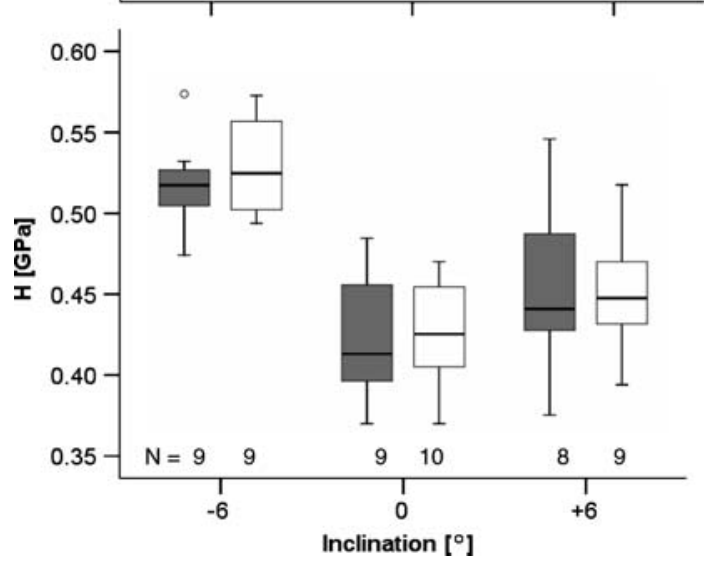

Fig. 9 Comparison of reduced elastic modulus $E_{\mathrm{r}}$ and hardness $H$ of neighbouring cell walls $\mathrm{A}$ and $\mathrm{B}$ of a double cell wall by means of nanoindentation. $N$ is the number of indents performed

Acknowledgement J. Konnerth gratefully acknowledges financial support by the government of the city of Vienna: "Hochschuljubiläumsstiftung” under Grant No. H-2036/2006.

Open Access This article is distributed under the terms of the Creative Commons Attribution Noncommercial License which permits any noncommercial use, distribution, and reproduction in any medium, provided the original author(s) and source are credited.

\section{References}

1. Fratzl P (2003) Curr Opin Colloid Interface Sci $8: 32$

2. Page DH, Elhossei F, Winkler K (1971) Nature 229:252

3. Burgert I, Fruhmann K, Keckes J, Fratzl P, Stanzl-Tschegg SE (2003) Holzforschung 57:661

4. Burgert I, Keckes J, Fruhmann K, Fratzl P, Tschegg SE (2002) Plant Biol 4:9

5. Eder M, Stanzl-Tschegg S, Burgert I (2008) Wood Sci Technol 42:679

6. Wimmer R, Lucas BN, Tsui TY, Oliver WC (1997) Wood Sci Technol 31:131

7. Gindl W, Gupta HS (2002) Composites Part A Appl Sci Manuf 33:1141

8. Gindl W, Gupta HS, Schöberl T, Lichtenegger HC, Fratzl P (2004) Appl Phys A Mater 79:2069

9. Gindl W, Schoberl T (2004) Composites Part A Appl Sci Manuf 35:1345

10. Jakes JE, Frihart CR, Beecher JF, Moon RJ, Stone DS (2008) J Mater Res 23:1113

11. Konnerth J, Gindl W (2006) Holzforschung 60:429

12. Tze WTY, Wang S, Rials TG, Pharr GM, Kelley SS (2007) Composites Part A Appl Sci Manuf 38:945

13. Wang S, Lee SH, Tze WTY, Rials TG, Pharr GM (2006) In: Nanoindentation as a tool for understanding nano-mechanical properties of wood cell wall and biocomposites, Atlanta

14. Yu Y, Fei B, Zhang B, Yu X (2007) Wood Fiber Sci 39:527

15. Oliver WC, Pharr GM (1992) J Mater Res 7:1564

16. Gindl W, Reifferscheid M, Adusumalli RB, Weber H, Roder T, Sixta H, Schoberl T (2008) Polymer 49:792

17. Konnerth J, Harper D, Lee SH, Rials TG, Gindl W (2008) Holzforschung 62:91

18. Konnerth J, Valla A, Gindl W (2007) Appl Phys A Mater 88:371

19. Gierlinger N, Schwanninger M (2006) Plant Physiol 140:1246

20. Gierlinger N, Schwanninger M (2007) Spectrosc Int J 21:69

21. Page DH, Elhosseiny F, Winkler K, Lancaster APS (1977) Tappi J 60:114

22. Swadener JG, Rho JY, Pharr GM (2001) J Biomed Mater Res A 57:108

23. Vlassak JJ, Nix WD (1993) Philos Mag A Phys Condens Matter 67:1045

24. Wiley JH, Atalla RH (1987) Carbohydr Res 160:113 